NBER WORKING PAPER SERIES

\title{
THE AMPLIFICATION OF UNEMPLOYMENT FLUCTUATIONS THROUGH SELF-SELECTION
}

\author{
Robert E. Hall \\ Working Paper 11186 \\ http://www.nber.org/papers/w11186
NATIONAL BUREAU OF ECONOMIC RESEARCH
1050 Massachusetts Avenue
Cambridge, MA 02138
March 2005

This research is part of the research program on Economic Fluctuations and Growth of the NBER. I am grateful to Dale Mortensen, Eva Nagypál, and Robert Shimer for helpful comments. A file containing data and programs will be available at Stanford.edu/rrehall The views expressed herein are those of the author(s) and do not necessarily reflect the views of the National Bureau of Economic Research.

(C) 2005 by Robert E. Hall. All rights reserved. Short sections of text, not to exceed two paragraphs, may be quoted without explicit permission provided that full credit, including $\odot$ ) notice, is given to the source. 
The Amplification of Unemployment Fluctuations through Self-Selection

Robert E. Hall

NBER Working Paper No. 11185

March 2005

JEL No. E24, E32, J64

\begin{abstract}
$\underline{\text { ABSTRACT }}$
Unemployment arises from frictions in the matching of job-seekers and employers. The level of resources that employers devote to evaluating applicants for jobs is a key factor in the magnitude of the frictions. Unemployment will be low if employers can review applicants cheaply. The cost of evaluation per hire depends on the fraction of applicants who are qualified for the job. Applicants may be better informed about their qualifications than are employers. If incentives induce selfselection by job-seekers, so that they apply mainly for jobs where they are qualified, friction and thus unemployment will be low. Self-selection is strongest in markets where unemployment is low and jobs are easy to find. Because of this positive feedback, the equilibrium in a market with selfselection is fragile-unemployment is sensitive to its determinants. Self-selection provides a mechanism for amplification of small changes in the determinants of unemployment.

Robert E. Hall

Hoover Institution

Stanford University

Stanford, CA 94305-6010

and NBER

rehall@stanford.edu
\end{abstract}




\section{Introduction}

Persistent high unemployment following a recession is a central puzzle of macroeconomics. When unemployment is high, jobs are hard to find, so the opportunity cost to the job-seeker for taking a given job is low. The marginal revenue product of labor appears to be only slightly diminished in a slack labor market-recessions are not the result of a collapse of productivity. The joint surplus enjoyed by an employer and worker hired into a newly created job is unusually high. Were both parties to respond to the enlarged surplus by redoubling their efforts to locate each other, unemployment would melt away quickly. An important friction prevents them from accomplishing this.

Since J.M Keynes focused the attention of economists on the puzzle, wage stickiness has been the most important culprit. The simple idea that the wage remains too high in a recession to permit the employment of the normal fraction of the labor force retains a firm grip on macroeconomics. But coherent fundamental explanations of sticky wages have eluded macroeconomics.

The past 20 years have seen the development of a widely accepted theory of non-wage frictions in the labor market. Mortensen and Pissarides (1994) is a major milestone in the development of the model. The friction arises from probabilistic matching of job-seekers and employers in a setting where the resources deployed by employers control the matching rate. The model portrays an equilibrium where employers expand matching effort up to the point that it exhausts the profit they expect from an additional hire. After a disturbance, the model reaches a new equilibrium rapidly because employers expand recruiting effort if unemployment is unusually high. Flexible wages play a key role in the model—higher employment reduces wages by lowering the opportunity cost of job seekers. The equilibrating force in the model is so strong that it cannot come close to matching the observed volatility of unemployment from booms to recessions, a point made recently by Shimer (2005).

This paper explores a different source of friction that limits or even eliminates employers' incentives to increase recruiting activity when unemployment is high. The model contains a countervailing force sufficiently powerful to offset the basic drive to create jobs when job-seekers' opportunity costs are low. In normal times, job-seekers self-select when applying for jobs. They visit only the employ- 
ers where they will be most productive. But when unemployment is high, jobseekers are less selective, because it pays to take less remunerative jobs when their opportunity costs are lower thanks to low probabilities of finding other jobs soon. Employers find themselves besieged by less qualified applicants.

In December 2002, the Wall Street Journal reported:

With 8.5 million Americans looking for work, it should be relatively easy for employers to find the right person for a job. Not so at 7Eleven Inc. The Dallas convenience-store chain needs to fill fieldmanagement positions and has piles of resumes. But locating applicants with the right skills has proven as tough, if not tougher, than during the boom times, the company says. Why? People looking for work are being less selective, applying for positions for which they aren't necessarily well-suited. That makes the task of sifting through applicants more difficult. "In good times people use the rifle approach for their job search. When people are skittish, they tend to use the shotgun," says Joe Eulberg, 7-Eleven's vice president of human resources. With the national unemployment rate at $6 \%$, many companies are finding themselves flooded with candidates who don't fit into job openings. "Our officers are getting inundated," says Dan Kaplan, director of recruiting for Washington, D.C., mortgage giant Fannie Mae, which is looking to fill routine slots. "At times, you're looking at volumes of resumes. It muddies up your thinking. You may settle [for a less-than-ideal candidate] because it's easy to."

The model of this paper captures the phenomenon described in this article.

Recent research applying the matching model to aggregate fluctuations in unemployment has taken productivity as the underlying exogenous driving force. The model in this paper takes a different point of view. As in the standard MortensenPissarides model, changes in productivity have only small effects on unemploymentsee Shimer (2005). The amount of self-selection in the market is actually invariant to productivity in my model. Self-selection is sensitive to other factors, notably changes in how well informed job-seekers are about their qualifications for the jobs that employers are trying to fill.

This paper can be seen as a rehabilitation of the reallocation theory of un- 
employment fluctuations, Lilien (1982). In its original form, that theory ascribed periods of high unemployment to shocks that caused shrinkage of some sectors and expansion of others. Abraham and Katz (1986) challenged that view by observing that vacancies should rise along with unemployment during periods of reallocation. Vacancies and other measures of recruiting effort, such as help-wanted advertising, actually fall substantially in recessions. In the new version of the reallocation theory based on the idea in this paper, the shocks and resulting movements of workers alter the level of knowledge about the likelihood of being qualified. I show that unemployment is higher-potentially much higher—when job-seekers are less informed. Though this paper does not spell out the mechanism, it seems reasonable that an alteration in the industry composition of labor demand, such as the collapse of IT employment in 2001, would reduce knowledge in this way.

It goes almost without saying that the core of the model in this paper comes from Akerlof (1970). Purchasers (here, employers) are ignorant of information known to sellers (here, job-seekers) but make an inference in which the seller's desire to trade is an important piece of information. The subsequent literature on adverse selection in the labor market is much too extensive to summarize adequately here. The model developed here has some points of resemblance to Montgomery (1999). The labor market in that paper can have self-sustaining cycles as the hiring policies of employers respond to the mix of good and bad workers among the pool of job-seekers.

\section{Implications of Imperfect Information about Qualifica- tions}

In the model, a job-seeker observes the value of a random variable, $y$, that contains information as to whether the job-seeker is qualified for a particular job. The jobseeker decides whether to apply for the job based on the value of $y$. The employer's only immediate knowledge about match productivity is that the worker has decided to apply. The employer then evaluates every applicant and determines whether the worker is truly qualified.

Job-seeker and employer are risk-neutral. Let $Q$ denote the event "applicant is qualified" and $N$ the event "applicant is not qualified" The job-seeker is concerned with 


$$
x=\operatorname{Prob}[Q \mid y],
$$

chooses a cutoff value of $x, x^{*}$, and applies for a job when $x$ meets the cutoff. I assume that $x$ is strictly increasing in the signal $y$ and denote the inverse of their relationship $y=\phi(x)$. The employer is concerned with

$$
q\left(x^{*}\right)=\operatorname{Prob}\left[Q \mid x \geq x^{*}\right]=\operatorname{Prob}\left[Q \mid y \geq \phi\left(x^{*}\right)\right],
$$

the likelihood that an applicant is qualified, which determines the payoff to the investment in evaluating the applicant. I will make use of the selection premium ratio,

$$
\pi\left(x^{*}\right)=\frac{q\left(x^{*}\right)}{x^{*}} .
$$

I take the distributions of $y$ conditional on $Q$ and $N$ to be known to job-seekers and workers, along with the unconditional probability that a worker is qualified.

Job-seekers queue up or otherwise compete with each other for access to a flow of signals about job opportunities. The job-seeker applies for each job that meets the cutoff level of qualification likelihood, $x^{*}$. Application imposes a cost $k_{W}$ on the job-seeker. Employers incur a cost $k_{E}$ to determine for sure whether or not the applicant is qualified.

I assume that an employer cannot shift the cost of evaluation to job-seekersthe employer cannot charge an applicant a fee up front. In other words, the cost $k_{E}$ refers to an action by the employer hidden from the job-seeker. The model is consistent with additional costs, such as those of credentials issued by a trusted third party, but these costs are not part of $k_{E}$.

All qualified job-seekers bargain with their prospective employers over the wage. Qualified job-seekers are homogeneous and all matches enjoy a positive joint surplus, $S$. Following Mortensen-Pissarides, I assume that the resulting wage bargain divides the surplus in given proportions, with a fraction $\nu$ to the employer and the remainder to the worker. See Hall and Milgrom (2005) for a discussion of the conditions under which this would be a reasonable approximation to the outcome of bargaining within the framework of modern bargaining theory.

The essential feature of the model is that job-seekers make a marginal decision and employers respond to the average consequences of that decision. Job-seekers set their cutoff signal to the point where they are indifferent between the expected 
benefit from applying or going on to the next opportunity. They enjoy a rent arising from the value in excess of the application cost that all opportunities with signals above the cutoff will deliver. As in Mortensen-Pissarides, employers create opportunities up to the point that their average subsequent value just equals the evaluation cost. Employers earn no rent.

The job-seeker sets the cutoff value, $x^{*}$, at the level where the worker's share of the expected surplus just pays for the cost of applying:

$$
k_{W}=\beta x^{*}(1-\nu) S .
$$

Here $\beta$ is the one-period discount ratio, reflecting the delay between application and the onset of employment.

The representative employer is in equilibrium when its share of the expected surplus equals the cost of evaluating an applicant:

$$
k_{E}=\beta q\left(x^{*}\right) \nu S
$$

Dividing the employer's equilibrium condition by the job-seeker's condition gives a simple equilibrium condition for the cutoff point, $x^{*}$ :

$$
\pi\left(x^{*}\right) \frac{\nu}{1-\nu}=\frac{k_{E}}{k_{W}} .
$$

The selection premium $\pi\left(x^{*}\right)$ is the key object in the model. Under certain conditions, it is a relatively flat function - the payoff to selection, in ratio terms, is not sensitive to the selection point $x^{*}$. In that case, small changes in the determinants result in large changes in the amount of self-selection, indexed by $x^{*}$, and thus in large changes in unemployment and other measures of conditions in the labor market.

\section{Determinants of the Selection Premium, $\pi$}

Because the cutoffs considered here are of the form $x \geq x^{*}$, I use counter-cdfs of the generic form $F(y)=\operatorname{Prob}\left[y^{\prime} \geq y\right]$ with density $f(y)=-F^{\prime}(y)$. The signal $y$ has the counter-cdf $F_{Q}(y)$ for qualified applicants and $F_{N}(y)$ for unqualified ones. I let $\alpha$ denote the marginal or unconditional probability of being qualified. Thus the 
marginal distribution of $y$ is a mixture of two distributions, with mixing parameter $\alpha$ and marginal counter-cdf,

$$
F(y)=\alpha F_{Q}(y)+(1-\alpha) F_{N}(y) .
$$

The constructions of interest are

$$
x=\operatorname{Prob}[Q \mid y]=\frac{\alpha f_{Q}(y)}{\alpha f_{Q}(y)+(1-\alpha) f_{N}(y)}
$$

and

$$
q=\operatorname{Prob}\left[Q \mid y^{\prime} \geq y\right]=\frac{\alpha F_{Q}(y)}{\alpha F_{Q}(y)+(1-\alpha) F_{N}(y)} .
$$

These two equations define $q(x)$ implicitly. In addition, equation (8) defines the relation between $x$ and $y, y=\phi(x)$. The marginal counter-cdf of $x$ is $G(x)=$ $F(\phi(x))$.

\subsection{Alternative distributions of the signal, $y$}

I consider two specifications. In the first, the distribution of $y$ is exponential conditional on qualification $(Q)$ and non-qualification $(N)$ :

$$
\begin{aligned}
& F_{Q}(y)=e^{-\theta y} \\
& F_{N}(y)=e^{-y}
\end{aligned}
$$

with $\theta<1$, so that a higher value of $y$ signals a higher likelihood of qualification. I take $\theta=0.55$.

In the second specification, $y$ has a linear density with support $[0,1]$ :

$$
\begin{gathered}
F_{Q}(y)=1-(1+\theta) y+\theta y^{2} \\
F_{N}(y)=1-(1-\theta) y-\theta y^{2},
\end{gathered}
$$

where $\theta<1$. I take $\theta=0.98$.

Figure 1 shows the resulting selection premium ratio $\pi\left(x^{*}\right)$ for the two examples. Notice that $\pi\left(x^{*}\right)$ is decreasing and always greater than one. The figure illustrates a difference that will be centrally important in the model: The exponential distribution - and other distributions with unbounded upper support — corresponds to a selection premium that is moderate and only gently declining as the cutoff 


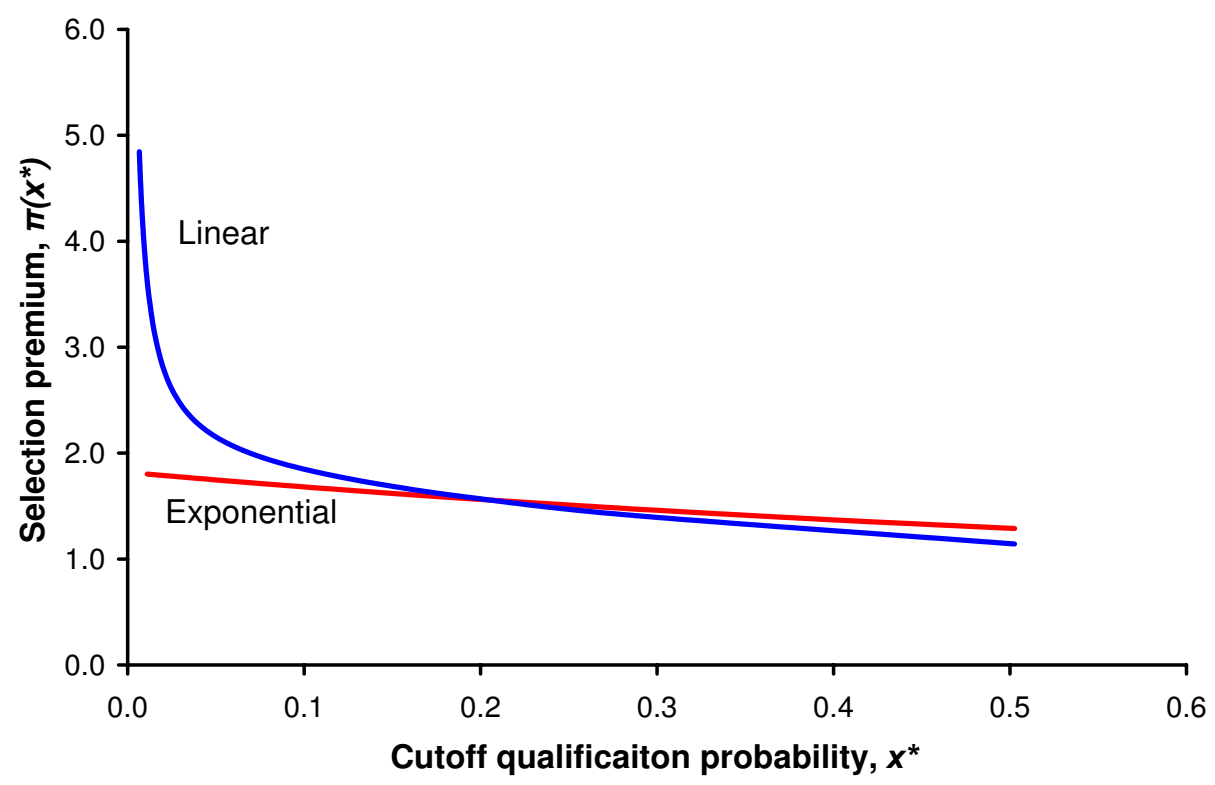

Figure 1. Selection Premiums for Two Specifications

rises. The linear density has a much higher premium low in its support and the premium falls to its minimum value of one as the cutoff approaches the upper bound of the support. The exponential case is more likely to generate large movements of $x^{*}$ in response to driving forces.

\subsection{Discussion of the exponential case}

In the rest of the paper, I will use the exponential case, which is highly tractable and generates interesting results. I will refer to $\theta$ as the noise parameter-as it approaches one, the signal contains more and more noise. At $\theta=1$, the signal conveys no information at all about a job-seeker's qualification.

In the calibration described in a later section, I take the likelihood of qualification for a random job of a random job-seeker to be $\alpha=0.02$. That is, a job-seeker is qualified for only two percent of the match opportunities. If the jobseeker elects to set $x^{*}$ to 0.11 , for example, then 11 percent of applications for jobs with this value of $x$ will bear fruit. Employers will find that $q(0.11)=18$ percent of applicants are qualified. An impressive amount of self-selection occurs 
in this example - an actual applicant is 9 times more likely to be qualified than is one chosen at random from the entire population of job-seekers.

The job-seeker has to consider a large number of potential jobs to achieve this amount of selection. The probability of finding an opening with a value of $x=0.11$ is

$$
G(0.11)=\frac{1}{176} \text {. }
$$

The job-seeker rejects 175 possibilities before finding one that has a sufficiently promising signal, $x$, that is, one that is at least 0.11 .

\subsection{The role of the noise parameter $\theta$}

Suppose that the noise parameter $\theta$ varies along with the cutoff qualification probability $x^{*}$, so as to satisfy the equilibrium condition equation (6) with constant values of $\nu, k_{W}$, and $k_{E}$. The equilibrium condition keeps the selection premium, $\pi$, constant. To see how $x^{*}$ responds to the variations in $\theta$, define the odds ratio

$$
R=\frac{e^{-y}}{e^{-\theta y}}=\frac{\operatorname{Prob}\left[y^{\prime} \geq y \mid N\right]}{\operatorname{Prob}\left[y^{\prime} \geq y \mid Q\right]}<1 .
$$

For the prescribed value of the selection premium ratio, $\pi$, the ratio has the closed form

$$
R=\frac{(\pi-1) \alpha \theta}{(1-\theta \pi)(1-\alpha)} .
$$

Substitute this result back into the definition of the qualification likelihood $x$ to obtain

$$
x^{*}=\frac{1-\theta \pi}{\pi(1-\theta)}
$$

and

$$
q=\pi x^{*}=\frac{1-\theta \pi}{1-\theta} .
$$

Notice that $x^{*}$ and $q$ are invariant to the unconditional qualification probability $\alpha$ among all pairs $\left(x^{*}, \theta\right)$ corresponding to the same selection premium, $\pi$. Notice also that $\alpha$, the overall fraction of job-seekers qualified for a given job, cannot be a driving force of fluctuations in the labor market, because $\pi$ is held constant by the equilibrium condition equation (6).

Figure 2 uses equation (17) to show the values of the cutoff likelihood $x^{*}$ corresponding to different values of the noise parameter $\theta$, as needed to achieve a 


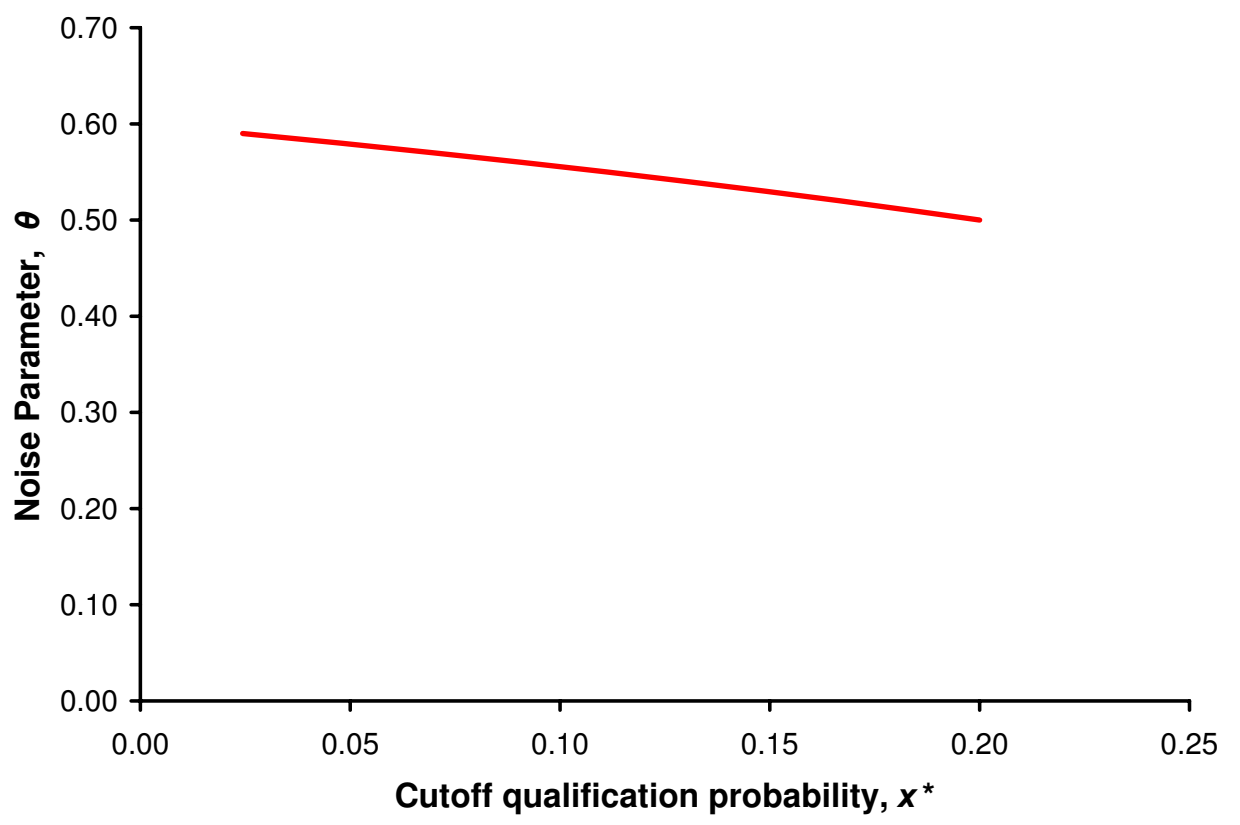

Figure 2. Tradeoff between noise parameter and cutoff likelihood, with selection premium held constant at 1.67

particular value of the selection premium, namely $\pi=1.67$. Notice that large changes in the cutoff correspond to relatively small changes in the noise parameter. This property is crucial to the amplification that occurs in the model about to be developed.

\section{Model of the Labor Market}

Parts of the model comes directly from Mortensen and Pissarides (1994). I examine the stationary state of the model, which is both the stochastic equilibrium of the processes of matching and job loss and the stationary economic equilibrium of the labor market. People in the model are either working or seeking jobs. They do not consider the possibility of leaving the labor force. In addition, they do not make any decision about how much to work once they are employed. The focus of the paper, as in the earlier papers in this tradition, is on the margin between work and search. 
Matching models generate unemployment through queuing that occurs in response to rents that are not absorbed through pricing. Unemployment arises for the same reason that a long line would form at a street corner if somebody gave a $\$ 20$ bill to everyone who came by the corner. In the Mortensen-Pissarides model, the rent is the share of the surplus that a successful job-seeker receives. The jobseeker does not incur any cost apart from the time spent waiting for an opportunity to arise. In this model, job-seekers do incur a cost, but the cost falls short of the full share of the surplus, so the difference between the two generates a rent that is dissipated by waiting, as in Mortensen-Pissarides.

I start by considering the values of job-seeking and employment. Job-seekers achieve a value $U$. The value arises from the flow of unemployment compensation and from the amenity of not working during the current spell of unemployment together with the earnings of subsequent jobs. I denote the combined flow value of unemployment compensation and the non-work amenity $\lambda$. All job-seekers have the same reservation wage $\underline{W}$. The present value of the surplus from a hire is $S$. Workers and employers split the surplus in fractions of $1-\nu$ and $\nu$. The applicant pays expected application fees, $a$, stated as a fraction of the part of the job surplus accruing to the worker. Upon finding a job, a worker receives an expected present value of wage of $\underline{W}+(1-a)(1-\nu) S+V$, the reservation wage plus the worker's share of the surplus net of application costs plus the value $V$ of the worker's career after the job ends. The searcher has a probability of starting a new job this period of $f$, the job-finding rate. The separation rate- the per-period probability that a job will end-is an exogenous constant $s$ (see Hall (2005b) for evidence supporting this proposition). The stationary condition for the unemployment value $U$ is

$$
U=\lambda+\beta\{f[\underline{W}+(1-a)(1-\nu) S+V]+(1-f) U\} .
$$

The stationary condition for $V$ is

$$
V=\beta[(1-s) V+s U] .
$$

The reservation wage is $\underline{W}=U-V$, the wage that makes the job-seeker indifferent between remaining unemployed at value $U$ and dropping to the lower post-wage value $V$ by becoming employed. I subtract equation (20) from equation (19) and 
solve for the job-finding rate:

$$
f=\frac{[1-\beta(1-s)] \underline{W}-\lambda}{\beta(1-a)(1-\nu) S} .
$$

The equation shows the basic property of matching models of unemployment- the job-finding rate reflects a choice between work and job-seeking and is higher to the extent that the payoff to work, measured by $\underline{W}$, is higher than the flow of benefits and amenities, $\lambda$.

The discount factor is $\beta$. The present value of the output produced by a worker is

$$
\frac{1}{1-\beta(1-s)} \text {. }
$$

The present value of the surplus from a hire is $S=\frac{1}{1-\beta(1-s)}-\underline{W}$.

Given the value of $x^{*}$, the value of the surplus, $S$, can be recovered from either equation (4) or (5). The value of the reservation wage, $\underline{W}$, comes from

$$
S=\frac{1}{1-\beta(1-s)}-\underline{W} .
$$

The job-finding rate comes from equation (21). Finally, the unemployment rate is the stationary probability of the two-state Markoff process,

$$
u=\frac{s}{s+f} .
$$

The resulting net surplus accruing to the job-seeker is

$$
(1-a)(1-\nu) S=(1-\nu) S-\frac{k_{W}}{q\left(x^{*}\right)}=\left(1-\frac{\beta}{\pi\left(x^{*}\right)}\right)(1-\nu) S .
$$

Recall from Sections 2 and 3 that the determinants of $x^{*}$ are the noise parameter $\theta$, the surplus share $\nu$, and the two costs, $k_{W}$ and $k_{E}$.

\subsection{The possibility of hiring without evaluation}

Under certain conditions, an employer could gain by foregoing evaluation for some or all applicants. Stiglitz (1975) noted that, under some conditions, an employer can maintain self-selection among applicants yet economize on screening cost by 
screening only a random subset of applicants. I assume that job-seekers are informed about an employer's evaluation policies. Accordingly, a job-seeker applying to an employer known to skip evaluation and to hire some or all applicants unconditionally will set a lower cutoff signal $\hat{x}^{*}$ than for an employer who screens all applicants. Let the fraction of applicants who are evaluated be $\psi$. The expected surplus net of testing cost accruing to the employer will be

$$
\nu\left\{\psi q\left(\hat{x}^{*}\right)\left[\frac{1}{1-\beta(1-s)}-\underline{W}\right]+(1-\psi)\left[\frac{q\left(\hat{x}^{*}\right)}{1-\beta(1-s)}-\underline{W}\right]\right\}-\psi k_{E} .
$$

The employer will achieve the highest net surplus by testing all applicants if

$$
\nu \frac{1-q\left(\hat{x}^{*}\right)}{1-\beta(1-s)} \underline{W}>k_{E},
$$

that is, if the avoided opportunity cost from hiring unqualified workers exceeds the testing cost as $\psi$ rises. Note that if this condition holds at the prevailing $x^{*}$ when all other employers are testing all applicants, it must hold at $\hat{x}^{*}$. I assume that the condition does hold, so that all employers choose universal testing.

\section{Calibration}

As in Hall (2005a), I calibrate to a job-finding rate of 60 percent per month and a separation rate of 3.5 percent per month, which imply an unemployment rate of 5.5 percent. As before, I take the noise parameter $\theta$ to be 0.55 , the unconditional likelihood of qualification to be $\alpha=0.02$, and the cutoff likelihood of qualification, $x^{*}$, to be 11 percent. I take the discount ratio to be $\beta=0.95^{1 / 12}$ and the flow value of unemployment compensation and leisure to be $\lambda=0.4$, which is a little more than 40 percent of the flow wage in equilibrium. I take the Nash parameter to be $\nu=0.5$, so the two sides split the surplus equally. I then solve the model for the values of the application cost, $k_{W}$, the testing cost, $k_{E}$, and the remaining endogenous variables. The values of the application and evaluation costs are $k_{W}=$ 0.208 and $k_{E}=0.347$. These costs are about 1 and 1.5 weeks of wages.

The criterion for evaluating every applicant, equation (27), is met by a wide margin at the calibrated values of the parameters and endogenous variables. 


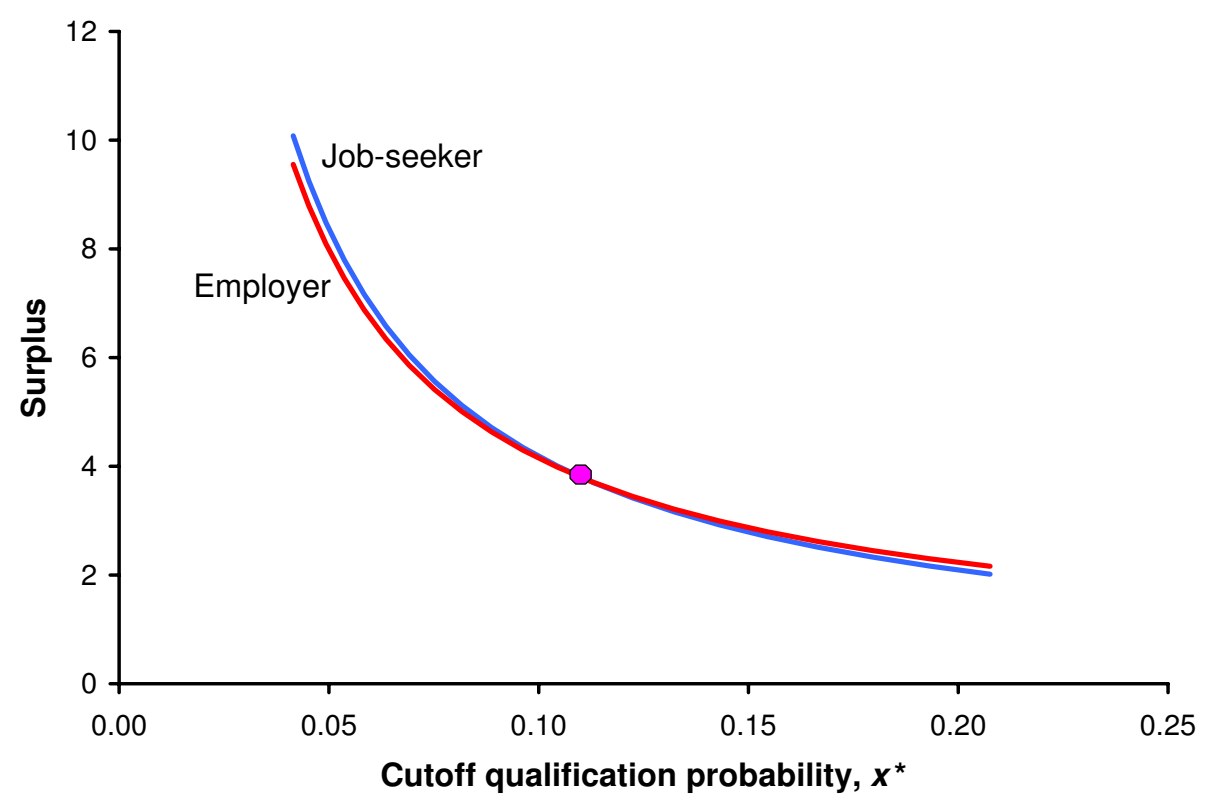

Figure 3. Joint determination of surplus, $S$, and application cutoff, $x^{*}$

\section{Properties of the model}

Figure 3 shows the joint determination of the cutoff level of the productivity signal, $x^{*}$, and the surplus, $S$. It plots the two equilibrium conditions, written as

$$
S=\frac{k_{W}}{\beta x^{*}(1-\nu)}
$$

and

$$
S=\frac{k_{E}}{\beta q\left(x^{*}\right) \nu} .
$$

The job-seeker curve cuts the employer curve from above. This is a standard stability condition and requires that the selection premium be decreasing in the cutoff likelihood. The curves correspond to the calibration to be developed shortly. The equilibrium is fragile in the sense that the two curves have similar slopes, so small shifts in the positions of the curves will result in large changes in the equilibrium.

The comparative statics of the model are straightforward. An increase in the job-seeker's application cost, $k_{W}$, shifts the job-seeker curve upward, raises the 


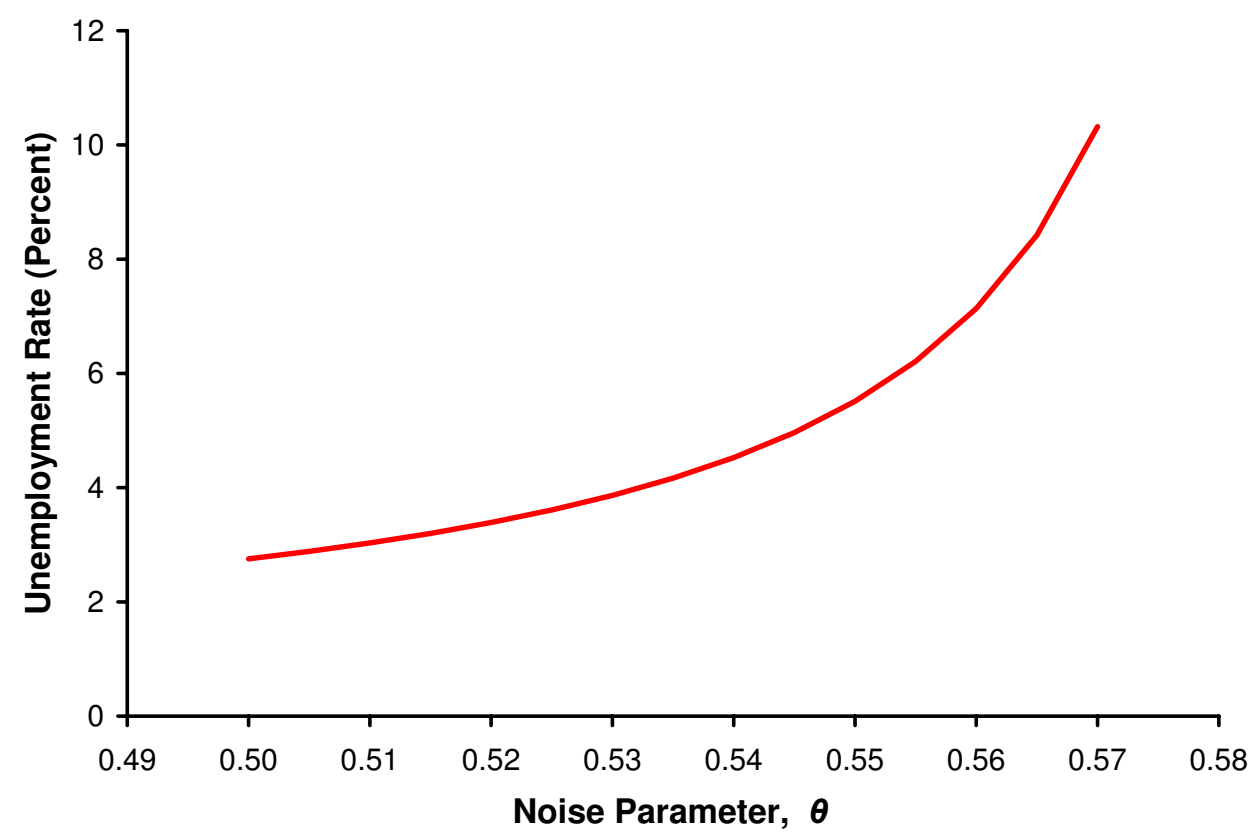

Figure 4. Response of unemployment to changes in the noise parameter, $\theta$

equilibrium cutoff signal, $x^{*}$, lowers the surplus of a job, and lowers unemployment. An increase in the employer's evaluation cost, $k_{E}$, shifts the employer curve upward, lowers the equilibrium cutoff signal, $x^{*}$, raises the surplus of a job, and raises unemployment. An increase in the noise parameter, $\theta$, shifts the employer curve upward, lowers $x^{*}$, raises $S$, and raises unemployment. If the productivity of successful matches were considered a parameter, instead of being held at one, it would not affect $x^{*}$.

Figure 4 shows the response of the unemployment rate to changes in the the noise parameter, $\theta$, keeping the overall likelihood that a given job-seeker is qualified for a given job, $\alpha$, and the other parameters constant. As $\theta$ rises, unemployment rises rapidly.

The model tells the following story about a recession. The story rests on the two equilibrium conditions for job-seekers and employers:

$$
\begin{gathered}
k_{W}=\beta x^{*}(1-\nu) S . \\
k_{E}=\beta x^{*} \pi\left(x^{*}\right) \nu S .
\end{gathered}
$$


A shock — such as the collapse of IT spending in 2001—diminishes the quality of the information that job-seekers have about their qualifications for jobs. The immediate response of employers is to cut back on recruiting, because the probability that an applicant is qualified, $q=\pi x$, declines below the cost of evaluating the applicant (equation (31)). Job-seekers then lower their cutoff point, $x^{*}$, which triggers a further reduction in recruiting. As unemployment rises because of the lower job-finding rate, job-seekers cut their reservation wage, $\underline{W}$, which raises the job surplus, $S$. As $x^{*}$ falls and $S$ rises, the market reaches a new equilibrium, where the new values allow job-seekers to cover their application costs and employers their evaluation costs. The process converges because the proportional effect of the decline in $x^{*}$ is greater for job-seekers (equation (30)) than for employers (equation (31)), because $\pi\left(x^{*}\right)$ is a decreasing function. On the other hand, the proportional effects are the same for the increase in the surplus.

At the calibrated parameter values, an increase in $\theta$ from 0.55 to 0.56 raises unemployment from its normal level of 5.5 percent to the recession level of 7.1 percent. The cutoff level of the qualification signal, $x^{*}$, falls from 11 percent to 9 percent. The job surplus rises from 3.8 months of production to 4.6. Because productivity does not change, the increase in the job surplus is entirely the result of a decline in the reservation wage present value from 21.8 months of production to 21.0 months. Whereas a job-seeker in normal times reviews 176 possibilities before applying for one, the number falls to 120 in the recession, because of a large increase in competition from other job-seekers.

\section{Concluding Remarks}

The static equilibrium model of this paper shows that self-selection is a key issue in the theory of labor-market frictions. I develop a tractable framework for investigating self-selection and show that it can provide a potent amplification mechanism. The model neither rests on fluctuations in productivity nor predicts cyclical fluctuations in productivity, thus overcoming one of the main defects of other views of unemployment volatility within the matching framework.

The driving force in the model is the quality of information about potential matches between job-seekers and employers. A slight decline in the quality of information results in a cascade of effects that substantially reduce the efficiency 
of the matching process. Employers are overwhelmed by less-qualified applicants and thus dissipate evaluation resources. Employers require a larger surplus from a match in order to finance the larger number of evaluations need to generate one match. The surplus available to job-seekers grows in proportion, and so does unemployment.

Although a decline in the quality of information about matches is a plausible event leading to a recession, measuring the decline is uncharted territory in labormarket research. 


\section{References}

Abraham, Katharine G. and Lawrence F. Katz, "Cyclical Unemployment: Sectoral Shifts or Aggregate Disturbances?," Journal of Political Economy, June 1986, 94 (3), pp. 507-522. Part 1.

Akerlof, George A., "The Market for 'Lemons': Quality Uncertainty and the Market Mechanism," The Quarterly Journal of Economics, Aug. 1970, 84 (3), 488-500.

Hall, Robert E., "Employment Fluctuations with Equilibrium Wage Stickiness," American Economic Review, March 2005. forthcoming.

, "Job Loss, Job Finding, and Unemployment in the U.S. Economy over the Past Fifty Years," February 2005. Department of Economics, Stanford University. Prepared for the NBER Macro Annual Conference, April 2005.

and Paul R. Milgrom, "The Limited Influence of Unemployment on the Wage Bargain," February 2005. Department of Economics, Stanford University.

Lilien, David M., "Sectoral Shifts and Cyclical Unemployment," Journal of Political Economy, August 1982, 90 (4), 777-93.

Montgomery, James D, "Adverse Selection and Employment Cycles," Journal of Labor Economics, April 1999, 17 (2), 281-97.

Mortensen, Dale T. and Christopher Pissarides, "Job Creation and Job Destruction in the Theory of Unemployment," Review of Economic Studies, 1994, 61 (0), pp. 397-415.

Shimer, Robert, "The Cyclical Behavior of Equilibrium Unemployment and Vacancies," American Economic Review, March 2005. Forthcoming.

Stiglitz, Joseph E., "The Theory of 'Screening,' Education, and the Distribution of Income," American Economic Review, June 1975, 65 (3), 283-300. 